
allemande

\title{
Gilbert KREBS, Les avatars du juvélinisme allemand
} 1896-1945

Paris, Presses Sorbonne Nouvelle, 2015

\section{Françoise Knopper}

\section{(2) OpenEdition}

\section{Journals}

Édition électronique

URL : https://journals.openedition.org/allemagne/610

DOI : 10.4000/allemagne.610

ISSN : 2605-7913

Éditeur

Société d'études allemandes

\section{Édition imprimée}

Date de publication : 29 décembre 2017

Pagination : $511-512$

ISSN : 0035-0974

\section{Référence électronique}

Françoise Knopper, «Gilbert kREBS, Les avatars du juvélinisme allemand 1896-1945 ", Revue d'Allemagne et des pays de langue allemande [En ligne], 49-2 | 2017, mis en ligne le 29 décembre 2017, consulté le 13 juin 2021. URL : http://journals.openedition.org/allemagne/610 ; DOI : https://doi.org/10.4000/ allemagne.610 


\section{Italiques}

Gilbert KREBS, Les avatars du juvélinisme allemand 1896-1945, Paris, Presses Sorbonne Nouvelle, 2015, 367 p., avec repères chronologiques, bibliographie, index et illustrations.

Gilbert Krebs, auteur de publications sur l'histoire de l'enseignement et la jeunesse allemande au XIXe siècle, publie ici une passionnante et exhaustive synthèse sur les mouvements de jeunesse qui ont vu le jour sous le règne de l'empereur Guillaume II et qui, au fil de mutations diverses, se sont prolongés jusque sous le Troisième Reich. Par «juvélinisme», traduction du terme allemand Jugendbewegung, l'auteur entend non pas «une organisation ou un ensemble d'organisations particulières mais un mouvement général, un mouvement social de défense de la 'cause des jeunes'» ( $p .11)$.

L'auteur pose une question primordiale: quel a été le rôle de la jeunesse allemande dans la montée en puissance du national-socialisme en Allemagne et le constat de la tragédie de cette jeunesse après 1933 ? L'interprétation que l'on trouve dans l'ouvrage est sans équivoque: l'orientation d'une partie des mouvements de jeunesse, avec leurs ferveurs utopiques et leur aveuglement, a débouché sur la dictature; malgré tout, leur idéologie n'était pas à confondre avec la Weltanschauung nazie, et elle leur a été confisquée.

Relevant le défi de devoir tenir compte de la disparité et de l'éparpillement des associations à étudier, d'autant que cette prolifération découlait de leur essence même puisque leurs aspirations étaient de permettre à chacun de développer librement sa personnalité tout en adhérant à des valeurs communes au groupe, G. Krebs analyse à la fois la création et l'évolution de ces mouvements et il les insère en tant que phénomènes générationnels dans leur contexte économique, social et politique.

L'ouvrage progresse donc par paliers chronologiques. Le premier présente les données politiques et économiques de l'Allemagne wilhelminienne ainsi que la critique émanant de penseurs influents (Nietzsche, Lagarde, Langbehn) et d'éducateurs proposant des réformes. La jeunesse s'organisait en associations confessionnelles et politiques, encouragées par la politique menée par l'État wilhelminien (Jugendpflege). Mais il y avait aussi de jeunes bourgeois qui, sans être révolutionnaires, se situaient - durant 
leurs loisirs - en marge de la société et mettaient en place leurs propres codes culturels, sportifs et romantiques. De là datent l'essor du Wandervogel, la prolifération d'associations autonomes, la rivalité entre Führer, la célèbre fête sur le Hoher Meissner en 1913 , la militarisation de ces jeunes gens et leur investissement dans la Première Guerre.

Pour le palier suivant, celui des années 1918-1933 - durant lesquelles la jeunesse ouvrière se structura à son tour -, l'auteur place l'accent sur les «Ligues juvélinistes» (Bündische Jugend). On mesure alors la diversité entre les associations à tendances internationalistes et pacifistes (proches de Marc Sangnier) et celles opérant une dérive fasciste, à la fois révolutionnaire et conservatrice, ni à droite ni à gauche. Selon G. Krebs, ce n'est pas tant la jeunesse allemande qui avait changé au début des années 1920, c'étaient les attentes de la société à l'égard de sa jeunesse. Mais, au début des années 1930, inversement, ce furent les mouvements de jeunesse autonomes qui s'interrogèrent sur la situation de la société allemande.

Et 1933-1945 seront les années noires de la jeunesse, avec l'embrigadement dans les Jeunesses hitlériennes ou la rébellion et la résistance de certains. L'auteur explicite les différences entre Hitlerjugend et Bündische Jugend et montre en quoi les pratiques originelles du Bund ainsi que l'utopie de réconciliation et d'harmonie sociale, dont les Ligues avaient rêvé, ont été utilisées et perverties par le NSDAP pour mettre les citoyens au pas ou pratiquer une politique d'exclusion.

Cet ouvrage fera date autant pour sa scientificité que pour sa clarté, pour sa documentation originale et riche, ses informations amples et précises, et la rigueur des interprétations. Et ce d'autant plus que, en Allemagne, l'intérêt pour cette jeunesse s'est trouvé réactualisé en 2013 avec les commémorations de la fête du Meissner et une grande exposition à Nuremberg: en témoignent les thèses récentes ou en cours. En France, la question a été récemment traitée en lien avec les origines intellectuelles du Troisième Reich (J. Bouveresse) ou avec les enjeux esthétiques du culte de la jeunesse allemande autour de 1900 (M. Cluet). Par ailleurs, M. Cluet a édité avec M. Mombert un numéro spécial de la revue strasbourgeoise Recherches Germaniques (2009), sous le titre Mouvements de jeunesse, jeunes en mouvement, qui se rapproche de la thématique du présent ouvrage mais dont les articles traitent d'objets spécifiques (pédagogie, iconographie, religion) et présupposent une connaissance préalable de l'arrière-plan.

Avec les liens entre les données sociales, démographiques, politiques et intellectuelles des époques traitées, avec l'analyse des facteurs de continuité et de rupture, c'est une rétrospective complète qui est offerte par la présente monographie de G. Krebs. Elle pourra intéresser historiens, politologues, germanistes, pédagogues, et tout spécialiste des mouvements de jeunesse connaissant ou non l'allemand. 